\title{
Influence of social learning on the completion rate of massive online open courses
}

\author{
R. A. Crane ${ }^{1}$ (1) S. Comley ${ }^{2}$
}

Received: 11 August 2020 / Accepted: 14 October 2020/ Published online: 21 October 2020

(C) The Author(s) 2020

\begin{abstract}
Massive open online courses (MOOCs) are now well-established as a highly effective, flexible and large participation capacity distance learning tool. They have enabled unprecedented access to educational material for millions of people worldwide, however, still suffer from significant student non-completion. Various theories have been proposed but we still lack a comprehensive understanding of why such attrition occurs. Herein we have analysed data from all MOOCs offered by the University of Exeter (UK) in 2018 in order to investigate whether "Social Learners" (i.e. those which comment on MOOC forums) exhibit differential non-completion than "Non-Social Learners". Results demonstrate that the former are considerably more likely to complete MOOCs, with median steps (i.e. "click points" within each MOOC) accessed (as a percentage of total steps) for Social and Non-Social Learners ranging from 50 to $100 \%$ and 9-46\% respectively. In addition, the number of Non-Social Learners enrolled onto each MOOC was consistently greater than the number of Social Learners, with ratios of Non-Social Learners to Social Learners for each MOOC ranging from 1.75-11.30. Results therefore suggest that whilst Social Learners are in the minority Social Learning is an important tool to prevent student attrition. More research is therefore required in order to further understand the multifaceted value of Social Learning (i.e. technical vs purely social) in order to inform future MOOC design to maximise such benefits for students.
\end{abstract}

Keywords Massive open online courses · MOOCs · Social learning · Distance education · Collaborative learning $\cdot$ Social networking

R. A. Crane

r.crane@exeter.ac.uk

S. Comley

s.comley@exeter.ac.uk

1 Camborne School of Mines, College of Engineering, Mathematics and Physical Sciences,

University of Exeter, Penryn Campus, Penryn, Cornwall TR10 9FE, UK

2 Technology Enhanced Learning team, Education and Student Support, University of Exeter,

Penryn Campus, Penryn, Cornwall TR10 9FE, UK 


\section{Introduction}

Access to education is widely considered a critically important mechanism to aid social mobility. The substantial increase in the use of free or "low-cost" online educational tools in recent years has represented a major step forward in the education of people who are less able to enrol in more traditional educational activities (e.g. paid University courses) due to, for example, cost, geographic location or caring responsibilities (Tsai et al. 2018). Within this in recent years we have seen the emergence of massive open online courses (MOOCs) who are defined as online courses with unlimited student participation. They are typically offered by Universities for a wide range of rationales, including as a marketing tool, to widen research impact or to prepare incoming students (Kaplan and Haenlein 2016). Furthermore there are also many different motives for MOOC enrolment ranging from career development to simply satisfying curiosity (Kaplan and Haenlein 2016).

In 2018 over 80 million students enrolled in approximately 10,000 MOOCs offered by more than 800 different universities. In comparison approximately 35 million students enrolled in MOOCs provided by approximately 500 universities in 2015 (Colas et al. 2016). As such MOOC availability and student participation is currently undergoing major global expansion and further information is required in order to understand how MOOCs can be created for maximum personal and societal benefit. MOOC creation is typically a relatively expensive process and as such it is critical that each MOOC is both economically sustainable and pedagogically effective (i.e. deliver the intended learning outcomes to a sufficient number of students) (van de Oudeweetering and Agirdag 2018). MOOC funding is often provided by the MOOC creator (i.e. the academic via a research grant rather than from the institution) (Richter and Krishnamurthi 2014). This is a relatively sustainable business model because each MOOC is funded by a specific grant in order to deliver a specific academic and/or educational impact. Care must be taken, however, that each MOOC is created with an inbuilt capability to enable students to maintain enthusiasm throughout in order to deliver the intended learning outcomes (Vitiello et al. 2018).

\subsection{Social learning in MOOCs}

There are two main types of MOOC: xMOOCs and cMOOCs (Mohamed and Hammond 2018). The former is characterised by the use of conventional e-learning platforms which are typically individually orientated, well defined and instructional, whilst the latter is characterised as more focussed on social learning (i.e. connectivity and cooperation between learners). Whilst these two distinct types of MOOC serve different purposes the multifaceted functionality of most MOOCs dictates, however, that they can often be a blend of the two (Conole 2016). It is therefore apparent that whilst particular MOOCs can be considered as ideally suited for certain students they can simultaneous be considered poorly suited for other types of students (Hew and Cheung 2014). MOOCs generally exhibit low completion rates (currently averaging approximately 10\% (Fidalgo-Blanco et al. 2016; Jordan 2013) which highlights the need to investigate and refine the current model. Many explanations have been postulated, however, one of the most common arguments regards the fact that MOOCs are typically free and relatively quick and easy to enrol onto, which in addition to their 
"attractive layout" (i.e. high quality graphics), dictates that individuals can be attracted to enrol without the full capacity, motivation and/or intention to continue to the end (Aguaded-Gómez 2013; Wong 2016).

Social learning (i.e. connectivity and cooperation between learners) is a key aspect of many MOOC platforms because it can enable scalable peer-based learning and as such is likely to be a highly useful tool to maintain continued student motivation (Brinton et al. 2014). Indeed social learning has also been demonstrated as effective at raising student satisfaction via alleviating feelings of isolation and lack of impersonal interactions (Lee et al. 2011; Li et al. 2014). Social learning in a MOOC can be instigated by a call to action that will prompt learners to engage in discussion with the wider cohort, share experiences or reflect on their learning with others.

Whilst anecdotally the feedback around these social learning activities has been positive, and the platform provider encourages a social learning approach there is very little data, that currently exists on the impact social learning has on the completion rate of MOOCs (Onah et al. 2014). An obvious unanswered question is therefore: Do social learners generally complete more steps within a MOOC than non-social learners?

This work has been established in order to provide preliminary data in order to answer this question. The University of Exeter currently offers 12 MOOCs which are all hosted via the FutureLearn platform (www.futurelearn.com), and several more are currently in preparation. They cover a range of topics, with titles ranging from: "Who Made My Clothes?" to "Genomic Medicine: Transforming Patient Care in Diabetes" to "Learn About Weather." Such MOOCs have been created using a diverse range of funding mechanisms and for various different (interconnected) rationales, however, they all include inbuilt tools for students to undertake social learning. Herein the completion rate (i.e. number of steps accessed) by students who are defined as social learners (i.e. individuals which have left one comment or more on the MOOC forum) has been compared to those who are defined as non-social learners (i.e. individuals which have left no comments on the MOOC forum) has been analysed. Results are intended to inform the development of future MOOCs in order to maximise their utility as next generation learning platforms.

\subsection{Methodology}

Two data files were downloaded for each of the MOOCs offered by the University of Exeter in 2018: one containing data on the total number of "steps accessed" (hereafter called the "steps accessed files") by each student and one containing data on which specific step the students have each commented on (hereafter called the "comments files"). Within this "steps" are defined as discrete sections of each MOOC (e.g. a slide or panel) which requires the student to then click a button to then access the next "step." Eight MOOCs were analysed: Empire: the Controversies of British Imperialism; Who Made My Clothes?; Genomic Medicine: Transforming Patient Care in Diabetes; Climate Change: The Science; Climate Change: Solutions; Learn About Weather; Valuing Nature: Should We Put a Price on Ecosystems?; and Tipping Points: Climate Change and Society. Individual users were identifiable with a unique 32 digit identification code (hereafter their "user ID"), however, no link was made between this, their personal details, or the specific comments they made and as such their identity remained anonymous. Moreover all comments in the "comments files" were identified by a date and time signature only (i.e. the actual comment was not viewed). 
Social learners (i.e. students who have commented once or more) were first isolated from the "comments files" by removing all of the "user ID" duplicates, using the automated "remove duplicates" function in Microsoft Excel.

The number of steps accessed for each user in the "steps accessed files" was then sorted in descending order. Each MOOC followed a different notation for each steps (e.g. 1.1, 1.2, 1.3, 1.4, 2.1, 2.2, etc. or 1.1, 1.2, 2.1, 2.2, 2.3, 2.4). In order to normalise this, each step was assigned an integer, ascending from 1. The "remove duplicates function" was then used to delete all duplicate data and thus leave the data correlating to the highest step accessed by all students (i.e. the both Social Learners and the NonSocial Learners). The highest step accessed by each Social Learner was then determined using a VLOOKUP function (i.e. by correlating with the "user ID" from the "comments file"). The total number of users completing each step was then determined using a COUNTIF function. The highest step accessed by each Non-Social Learner was then determined by using a IFERROR function (i.e. to determine which users were not included in the Social Learner list) followed by an IF function (i.e. to state the number of steps accessed for each user that was not included in the Social Learning list). The total number of users accessing each step was then determined using a COUNTIF function. Data were then normalised to percentage of each cohort, with Social Learners and Non-Social Learners treated as being within separate cohorts.

\section{Results and discussion}

Table 1 displays the Ratio of Non-Social Learners to Social Learners for each MOOC. It can be observed that the number of Non-Social Learners enrolled onto each MOOC was consistently greater than the number of Social Learners, with ratios ranging from 11.30 for "Genomic Medicine: Transforming Patient Care in Diabetes" to 1.75 for "Valuing Nature: Should We Put a Price on Ecosystems?" (Table 1). This demonstrates that noncollaborative learning is currently the most common mode of learning for all MOOCs.

Figure 1 displays the number steps accessed as a function of the percentage of the cohort for Social Learners and Non-Social Learners. A clear difference can be observed between the number of steps accessed by the Social Learners and the Non-Social Learners, with the latter accessing significantly more steps. Table 2 displays median

Table 1 Ratio of Non-Social Learners to Social Learners for each MOOC

\begin{tabular}{ll}
\hline MOOC name & Ratio of Non-Social Learners to Social Learners \\
\hline Climate Change: The Science & 2.24 \\
Climate Change: Solutions & 2.29 \\
Empire: the Controversies of British Imperialism & 9.38 \\
Genomic Medicine: Transforming Patient Care in Diabetes & 11.30 \\
Learn About Weather & 4.41 \\
Tipping Points: Climate Change and Society & 2.60 \\
Valuing Nature: Should We Put a Price on Ecosystems? & 1.75 \\
Who Made My Clothes? & 3.89 \\
\hline
\end{tabular}



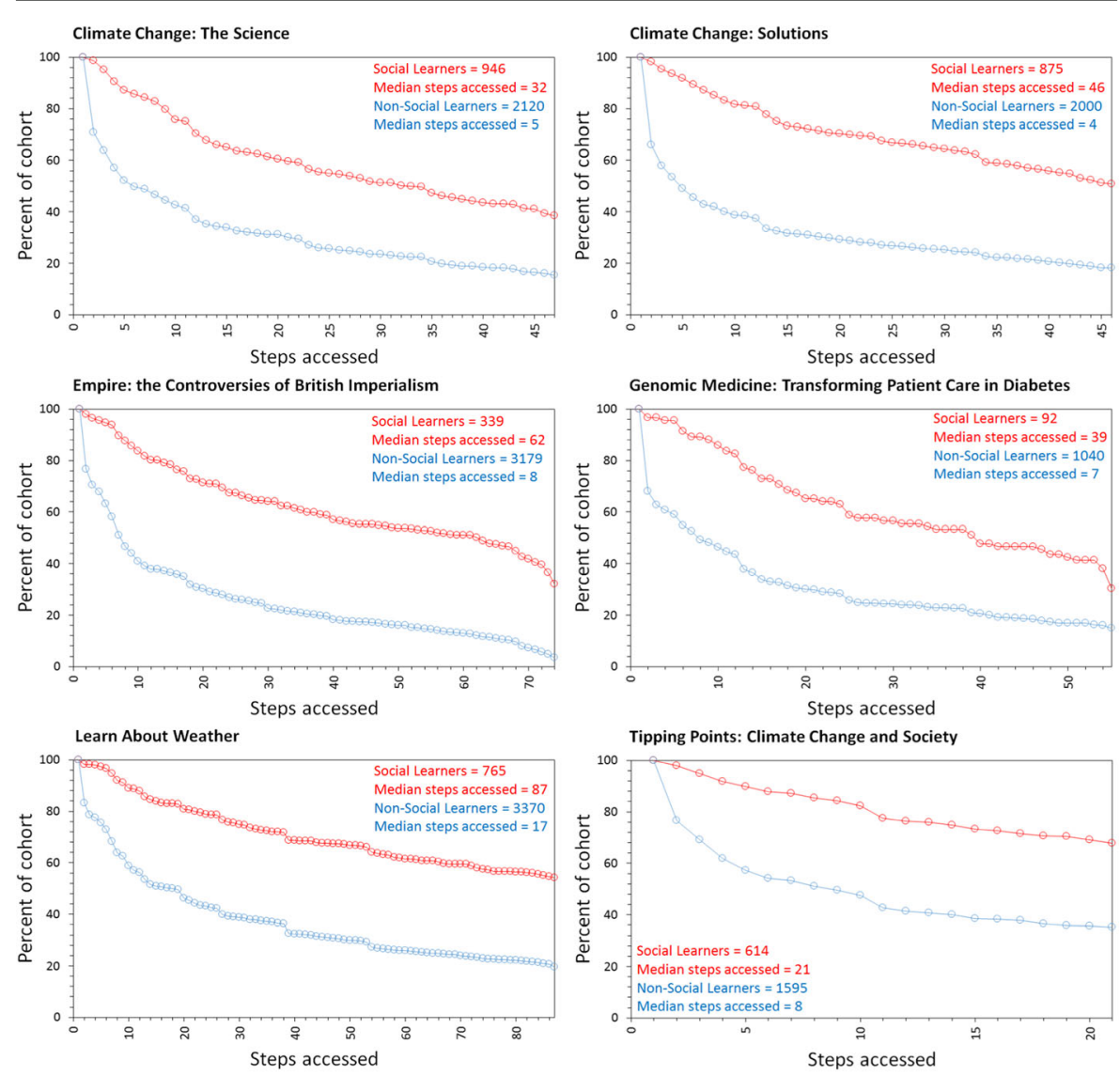

Valuing Nature: Should We Put a Price on Ecosystems?
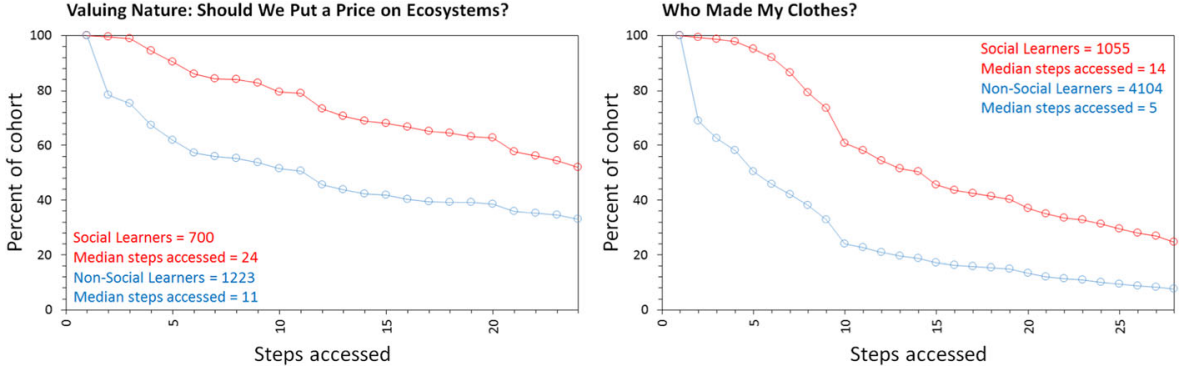

Fig. 1 Steps accessed as a function of the percentage of the cohort for Social Learners and Non-Social Learners. Social Learners and Non-Social Learners are considered as within separate cohorts in order for direct comparison. Social Learners are defined as learners which have written one or more comment

and mean steps accessed (as a percentage of total steps) for Social and Non-Social Learners. Median values ranged from $100 \%$ and $9 \%$ respectively for "Climate Change: Solutions" to $100 \%$ and $46 \%$ respectively for "Valuing Nature: Should We Put a Price on Ecosystems?" Mean values ranged from $70 \%$ and $32 \%$ respectively for "Climate Change: Solutions" to $57 \%$ and $28 \%$ respectively for "Who Made My Clothes?". This demonstrates that Social Learners are considerably more likely to complete MOOCs and conversely Non-Social Learners are considerably more likely to decline in their 
Table 2 Median and mean steps accessed (as a percentage of total steps) for Social and Non-Social Learners

\begin{tabular}{|c|c|c|c|c|}
\hline MOOC name & $\begin{array}{l}\text { Median: Social } \\
\text { Learners }\end{array}$ & $\begin{array}{l}\text { Median: Non- } \\
\text { Social Learners }\end{array}$ & $\begin{array}{l}\text { Mean: Social } \\
\text { Learners }\end{array}$ & $\begin{array}{l}\text { Mean: Non- } \\
\text { Social Learners }\end{array}$ \\
\hline Climate Change: The Science & 68 & 11 & 61 & 32 \\
\hline Climate Change: Solutions & 100 & 9 & 70 & 32 \\
\hline $\begin{array}{l}\text { Empire: the Controversies of } \\
\text { British Imperialism }\end{array}$ & 74 & 13 & 75 & 40 \\
\hline $\begin{array}{l}\text { Genomic Medicine: Transforming } \\
\text { Patient Care in Diabetes }\end{array}$ & 71 & 13 & 63 & 31 \\
\hline Learn About Weather & 100 & 20 & 64 & 33 \\
\hline $\begin{array}{l}\text { Tipping Points: Climate Change } \\
\text { and Society }\end{array}$ & 100 & 38 & 81 & 50 \\
\hline $\begin{array}{l}\text { Valuing Nature: Should We Put } \\
\text { a Price on Ecosystems? }\end{array}$ & 100 & 46 & 75 & 51 \\
\hline Who Made My Clothes? & 50 & 18 & 57 & 28 \\
\hline
\end{tabular}

participation. It is worth noting that discussion forums within MOOCs generally include both technical and social content. Unfortunately in the current work it has not been possible to disentangle these two entities, however, it is likely that both would have acted to decrease the decline in participation for Social Learners. In addition the posting of comments on external forums (e.g. LinkedIn, Twitter, Facebook) has not been considered in the current work which may impact these data.

\subsection{Future prospects: Using social learning to foster student motivation for MOOC completion?}

The lack of completion rates for MOOCs has been attributed to numerous different factors, however, it is likely that the lack of face-to-face engagement with the teacher and fellow students, which can result in the feeling of isolation and disengagement, is a major contributor. As such the major challenge is to design MOOCs where such engagement can be facilitated.

Motivation is defined as an internal state that promotes, directs and sustains goalorientated behaviour (Bandura 2012). Glynn et al. (2011) suggests several entities which influence motivation in learning, including: personal relevance, self-determination, self-efficacy and extrinsic factors such as gaining a prize or avoiding a penalty. Many of these factors can either be directly or indirectly influenced by social learning. For example both self-determination (i.e. the level of control a student has over their learning) and self-efficacy (i.e. the confidence that a student has for achieving high outcomes) can be enhanced by engaging with peers in order to discuss course material and trouble-shoot problems. Furthermore social learning can also create a "student community" which can help maintain motivation due to a wide range of factors from simply providing the student with the knowledge that if they were to struggle to understand a concept then they could reach out to peers, to career development (i.e. networking with fellow students) (Kizilcec and Schneider 2015).

As well as having a positive impact on learner motivation, supporting an active social cohort can also enhance the inclusivity of a course. Providing space and well-designed 
opportunities for all learners to have a voice in the course can aid with learners feeling that they are a part of the learning community as opposed to watching from the side-lines.

Often a 'low stakes' ice-breaker activity may be set at the start of a course to engage learners. It can be less intimidating to contribute to a discussion when a learner does not feel they may be exposing their knowledge, or lack of, within a subject area. Where learners have commented once the data herein shows they are likely to continue to engage, having made that initial contribution and becoming part of the social cohort. Consequently it can be stated that there is a strong and real demand for future research into how we can design and implement MOOCs which foster and sustain Social Learning, and that Social Learning should remain a fundamental component of the "MOOC capability toolkit" into the future. Such research should, of course, be supplemented with enhanced knowledge of how to develop MOOC platforms which are palatable to Non-Social learners who may become dissuaded from continuing a MOOC which requires constant social engagement. Instead it is likely that Social Learning should remain optional (in most instances) in order to cater for the entire spectrum of students and within this the use of non-social motivational factors (e.g. prizes) will likely be similarly important.

\section{Conclusions}

MOOCs currently exhibit relatively low student completion rates which highlights the need to investigate and refine the current model. Herein the difference in student completion rate between "Social Learners" (i.e. those which have left at least one comment on a MOOC forum) and "Non-Social Learners" (i.e. those which have not left any comments on a MOOC forum) has been investigated using Data from all MOOCs offered by the University of Exeter in 2018. The following can be concluded:

(1) Social Learners are more likely to complete MOOCs than Non-Social Learners, with median steps accessed (as a percentage of total steps) for Social and NonSocial Learners, ranging from 50 to $100 \%$ and $9-46 \%$ respectively.

(2) Social Learner enrolment was consistently lower than Non-Social Learners, with ratios of Non-Social Learners to Social Learners for each MOOC ranging from 1.75-11.30.

Results therefore suggest that Social Learning is likely to be an important tool to prevent student discontinuation and steps must therefore be taken in the future in order to design MOOC platforms to enable and cultivate Social Learning. Within this it is important to constantly examine the nature of Social Learning (i.e. technical vs purely social) and how this correlates with student attainment, performance and satisfaction.

Acknowledgements We would like to thank Claire Lipscomb (Senior Partnership Manager) and colleagues at FutureLearn for facilitating access to MOOC data.

Authors' contributions All authors contributed to the study conception and design. Data collection were performed by Steph Comley and data analysis by Rich Crane. The first draft of the manuscript was written by Rich Crane and all authors commented on previous versions of the manuscript. All authors read and approved the final manuscript.Data availabilitydata is available upon request. 


\section{Compliance with ethical standards}

\section{Conflicts of interest/competing interests $\mathrm{n} / \mathrm{a}$}

\section{Code availability $n / a$}

Open Access This article is licensed under a Creative Commons Attribution 4.0 International License, which permits use, sharing, adaptation, distribution and reproduction in any medium or format, as long as you give appropriate credit to the original author(s) and the source, provide a link to the Creative Commons licence, and indicate if changes were made. The images or other third party material in this article are included in the article's Creative Commons licence, unless indicated otherwise in a credit line to the material. If material is not included in the article's Creative Commons licence and your intended use is not permitted by statutory regulation or exceeds the permitted use, you will need to obtain permission directly from the copyright holder. To view a copy of this licence, visit http://creativecommons.org/licenses/by/4.0/.

\section{References}

Aguaded-Gómez, J. I. (2013). The MOOC revolution: A new form of education from the technological paradigm? Comunicar, 21(41), 7-08.

Bandura, A. (2012). Going global with social cognitive theory: From prospect to paydirt. In applied psychology 2012 Oct 12 (pp. 65-92). Psychology Press.

Brinton, C. G., Chiang, M., Jain, S., Lam, H., Liu, Z., \& Wong, F. M. (2014). Learning about social learning in MOOCs: From statistical analysis to generative model. IEEE transactions on Learning Technologies, 7(4), 346-359.

Colas, J. F., Sloep, P. B., Garreta-Domingo, M. (2016). International review of research in open and distributed learning. The effect of multilingual facilitation on active participation in MOOCs.

Conole, G. (2016). MOOCs as disruptive technologies: Strategies for enhancing the learner experience and quality of MOOCs. RED: Revista de Educacion a Distancia, 50, 1-8.

Fidalgo-Blanco, Á., Sein-Echaluce, M. L., \& García-Peñalvo, F. J. (2016). From massive access to cooperation: Lessons learned and proven results of a hybrid $\mathrm{xMOOC} / \mathrm{cMOOC}$ pedagogical approach to MOOCs. International Journal of Educational Technology in Higher Education, 13(1), 24.

Glynn, S. M., Brickman, P., Armstrong, N., \& Taasoobshirazi, G. (2011). Science motivation questionnaire II: Validation with science majors and nonscience majors. Journal of Research in Science Teaching, 48(10), 1159-1176.

Hew, K. F., \& Cheung, W. S. (2014). Students' and instructors' use of massive open online courses (MOOCs): Motivations and challenges. Educational Research Review, 12, 45-58.

Jordan, K.. (2013). http://www.katyjordan.com/MOOCproject.html (accessed 22/11/18).

Kaplan, A. M., \& Haenlein, M. (2016). Higher education and the digital revolution: About MOOCs, SPOCs, social media, and the cookie monster. Business Horizons, 59(4), 441-450.

Kizilcec, R. F., \& Schneider, E. (2015). Motivation as a lens to understand online learners: Toward data-driven design with the OLEI scale. ACM Transactions on Computer-Human Interaction (TOCHI), 22(2), 6.

Lee, S. J., Srinivasan, S., Trail, T., Lewis, D., \& Lopez, S. (2011). Examining the relationship among student perception of support, course satisfaction, and learning outcomes in online learning. The Internet and Higher Education, 14(3), 158-163.

Li, N., Verma, H., Skevi, A., Zufferey, G., Blom, J., \& Dillenbourg, P. (2014). Watching MOOCs together: Investigating co-located MOOC study groups. Distance Education, 35(2), 217-233.

Mohamed, M. H., \& Hammond, M. (2018). MOOCs: A differentiation by pedagogy, content and assessment. The International Journal of Information and Learning Technology, 35(1), 2-11.

Onah, D. F., Sinclair, J., \& Boyatt, R. (2014). Dropout rates of massive open online courses: behavioural patterns. EDULEARN14 proceedings, 7, 5825-5834.

Richter, S. L., \& Krishnamurthi, M. (2014). Preparing faculty for teaching a MOOC: Recommendations from research and experience. International Journal of Information and Education Technology, 4(5), 411-415.

Tsai, Y. H., Lin, C. H., Hong, J. C., \& Tai, K. H. (2018). The effects of metacognition on online learning interest and continuance to learn with MOOCs. Computers \& Education, 121, 18-29. 
van de Oudeweetering, K., \& Agirdag, O. (2018). MOOCs as accelerators of social mobility? A systematic review. Journal of Educational Technology \& Society, 21(1), 1-1.

Vitiello, M., Walk, S., Helic, D., Chang, V., \& Guetl, C. (2018). User behavioral patterns and early dropouts detection: Improved users profiling through analysis of successive offering of MOOC. Journal of Universal Computer Science, 24(8), 1131-1150.

Wong, B. T. (2016). Factors leading to effective teaching of MOOCs. Asian Association of Open Universities Journal, 11(1), 105-118.

Publisher's note Springer Nature remains neutral with regard to jurisdictional claims in published maps and institutional affiliations. 